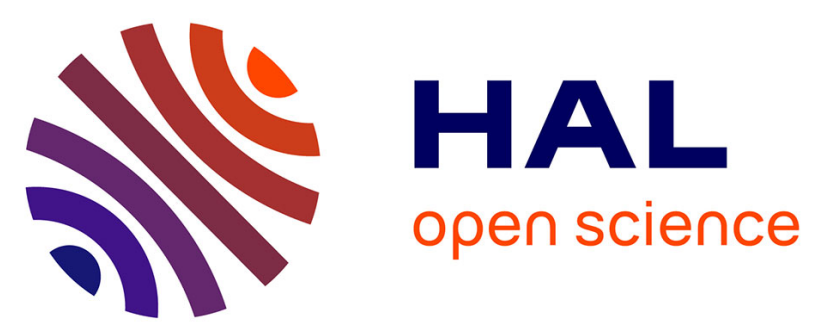

\title{
Development and validation of an SNP-based new set of markers useful for early selection for sharka disease in apricot (P. armeniaca)
}

Patrick Lambert, Carole Confolent, Guillaume Roch, Naïma Dlalah, Arnaud A. Remay, Anne Bernole, Véronique Decroocq, Clarisse Auvinet, Jean Marc Audergon

\section{To cite this version:}

Patrick Lambert, Carole Confolent, Guillaume Roch, Naïma Dlalah, Arnaud A. Remay, et al.. Development and validation of an SNP-based new set of markers useful for early selection for sharka disease in apricot (P. armeniaca). 17. International Symposium on Apricot Breeding and Culture, Jul 2019, Malatya, Turkey. , pp.1, 2019. hal-02790319

\section{HAL Id: hal-02790319 \\ https://hal.inrae.fr/hal-02790319}

Submitted on 5 Jun 2020

HAL is a multi-disciplinary open access archive for the deposit and dissemination of scientific research documents, whether they are published or not. The documents may come from teaching and research institutions in France or abroad, or from public or private research centers.
L'archive ouverte pluridisciplinaire HAL, est destinée au dépôt et à la diffusion de documents scientifiques de niveau recherche, publiés ou non, émanant des établissements d'enseignement et de recherche français ou étrangers, des laboratoires publics ou privés. 


\title{
Development and validation of an SNP-based new set of markers useful for early selection for sharka disease in apricot (P. armeniaca)
}

\author{
P. Lambert ${ }^{1}$, C. Confolent ${ }^{1,2}$, G Roch ${ }^{1,3}$, N. Dlalah ${ }^{1}$, A. Remay ${ }^{4}$, A. Bernole ${ }^{4}$, V. Decroocq ${ }^{5}$, C. Auvinet ${ }^{3}$ and JM. Audergon $^{1}$ \\ ${ }^{1}$ GAFL, INRA, 84140, Montfavet, France \\ ${ }^{2}$ UMR GEDC 5 chemin de Beaulieu, 63000 Clermont-Ferrand, France \\ ${ }_{3}^{3}$ CEP Innovation, 23 rue Jean Baldassini, 69364 Lyon cedex 7, France \\ ${ }^{4}$ BioGEVES, Domaine du Magneraud, BP 52, 17700 Surgères, France \\ ${ }^{5}$ Equipe de Virologie, UMR 1332 BFP, 71 avenue E. Bourlaux, CS 20032, \\ 33882 Villenave d'Ornon, France
}

\section{Context and objectives}

Sharka disease, due to the Plum pox virus, is a major threat to apricot trees. Most of the accessions world-wide and particularly those cultivated in Western Europe and the Mediterranean area are susceptible to the disease. A few resistance sources have been identified to date in cultivars developed in the US from a basis of Central Asian germplasm, all of these sharing the same genomic region associated with resistance to sharka in chromosome 1. Based on this, a set of two SSRs (PGS1.21 and PGS1.24) framing the MATH genes possibly responsible for the resistance, and an indel (ZP002) were developed in this region and were used for identifying and discarding susceptible individuals at the plantlet stage of the apricot breeding process. However, SSR markers could be difficult and costly to implement, particularly for small teams, due to the investment in hands-on time and equipment. It is the reason why we turned to Single nucleotide polymorphisms (SNP), taking advantage of the numerous apricot genomic sequences available at the UGAFL. The aim of this study was therefore to develop an alternative set of SNP-based markers, usable with the competitive allele-specific PCR (KASPTM) technique developed by LGC genomics, that could be cheaper and more easily implemented, and could thus beneficially replace the current SSR-based set.

\section{Material and Methods}

\section{Plant material}

A total of 765 accessions from various geographic origins including European, Mediterranean, North-African, Central and Eastern-Asian, Chinese, Japanese and North-American collections representing a wide range of the apricot diversity, as well as accessions from breeders, were tested in this study (Fig. 1 and Fig. 2).

\section{SNP identification and primer development}

Next-Generation Sequencing (NGS) data derived from seven resistant or susceptible apricot cultivars ('Stella', 'Goldrich', 'Greta', 'Bakour', 'Bergeron', 'Moniqui' and 'Super Rouge'), sequenced in the frame of the ANR CHEX ABRIWG project, were aligned onto the peach genome sequence V2.0. Regions encompassing or close to PGS1.21, PGS1.24 and ZP002 were examined for SNP/indel discovery and those including polymorphic SNP/indels between resistant and susceptible accessions were extracted. Primer-triplets (two competitive, allele-specific forward primers and one common reverse primer) were developed for each marker. They were compared to the peach genome sequence V2.0 with the Basic Local Alignment Search Tool (BLAST ${ }^{\circledR}$ ) in order to identify possible duplicate sequences outside of the target region. Those primer-triplets corresponding to single positions were kept for further analyses.

\section{Comparative genotyping and SNP-based markers validation}

SNP-based primer triplets were tested on a set of 24 accessions known for their resistance or susceptibility to PPV, using the PCR-based KASPTM (Kompetitive Allele Specific PCR) genotyping chemistry from LGC genomics. Three SNPbased markers, SP870, SP353 and SP871 (positions Pp01:8,527,007, 8,607,013 and 8,665,219 respectively) were selected and used for genotyping the whole set of 765 accessions (Fig. 3), in comparison with the three SSR-based markers, PGS1.21, ZP002 and PGS1.24 (positions Pp01: 8,527,819, 8,607,011 and $8,668,830)$ used before for genotyping. Results obtained were then compared.

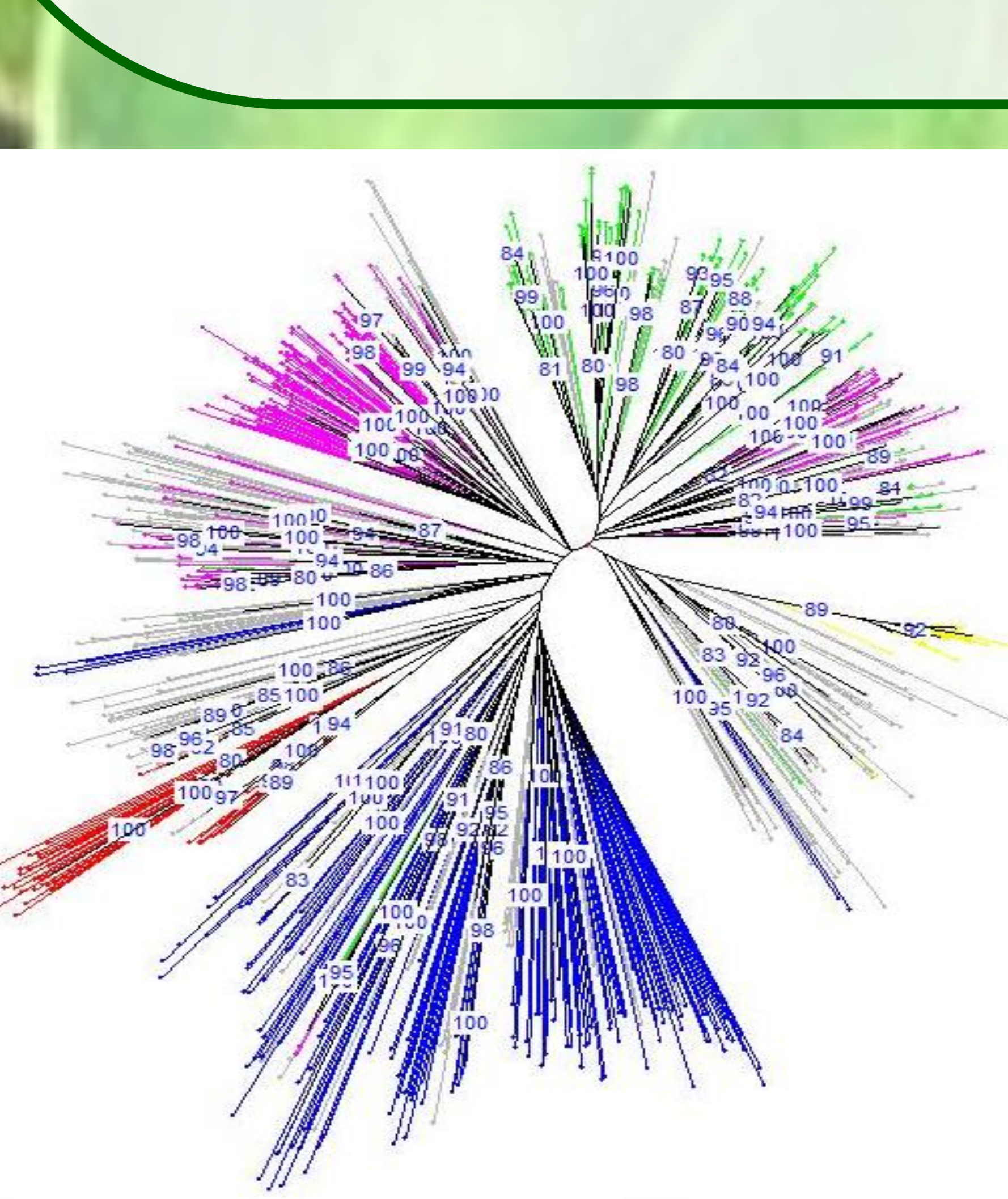

Fig. 2. Neighbor-joining dendrogram based on simple matching dissimilarity matrix showing relationships among the apricot accessions under study

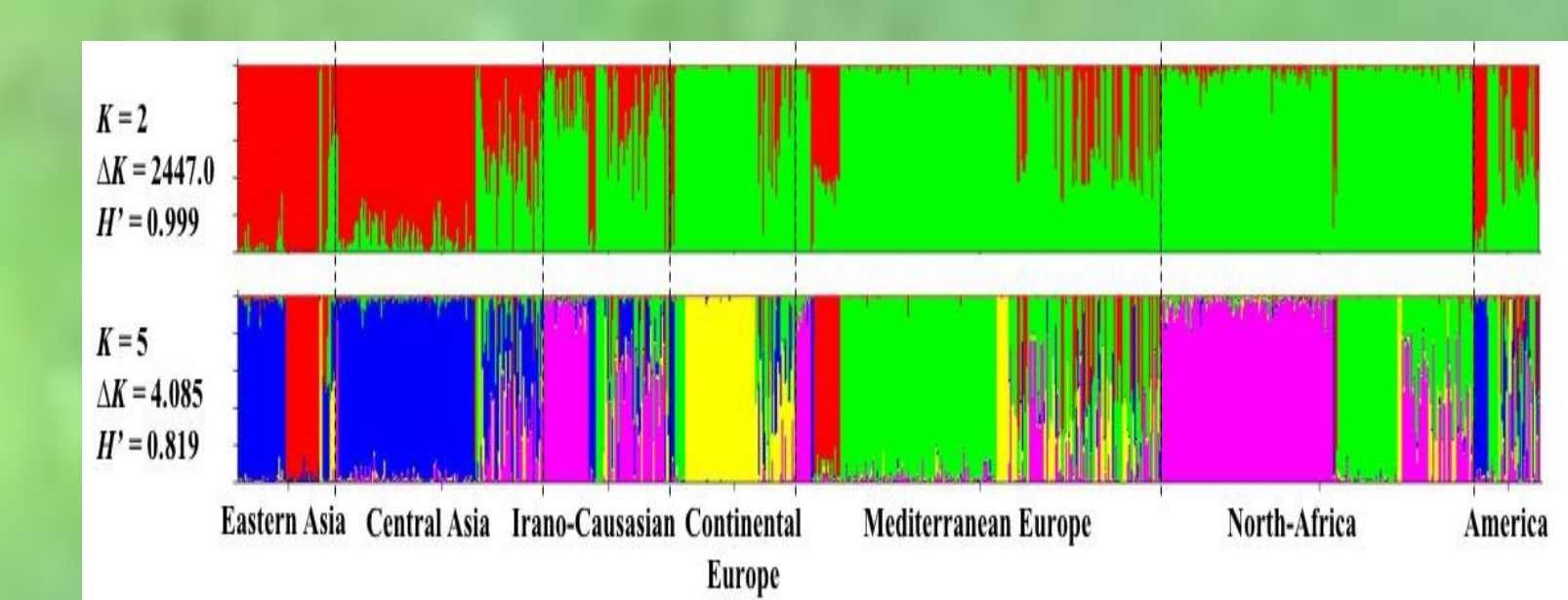

Fig. 1. Inference of population structure based on 25 SSRs using STRUCTURE software for $K=2$ and $K=5$.

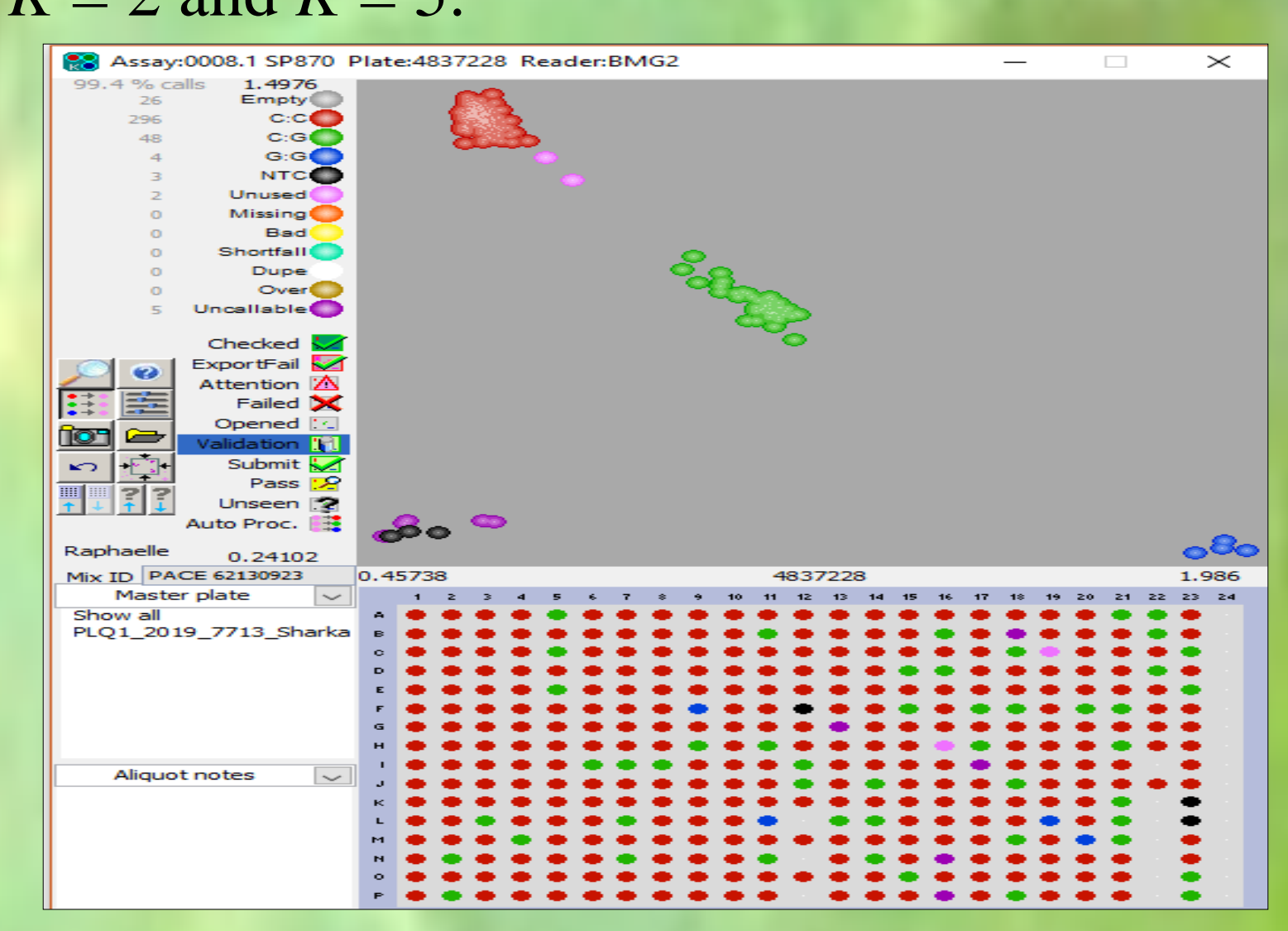

Fig. 3 SP 870 genotyping cluster-plot obtained using (KASPTM) technique. Heterozygous individuals are in the middle (green colour)

\section{Results}

When comparing each SSR/SNP couple individually (PGS1.21/SP870, ZP002/SP353 and PGS1.24/SP871), a perfect correlation of the results was observed for all the accessions, except for three, with the last two couples, ZP002/SP353 and PGS1.21/SP871 (Table 1). Conversely, results were less straightforward with PGS1.21/SP870: four alleles (330, 336, 338 and $340 \mathrm{bp}$ ) were found associated with the resistance allele (G) of SP870 in the 145 accessions involved. The allele $340 \mathrm{bp}$ was however the most frequently associated with the resistance SNPallele (101/156), followed by the allele 338 bp (47/156), $330 \mathrm{bp}$ (4/156) and $336 \mathrm{bp}$ (2/156). When comparing these results with the phenotype of the accessions for which it was available, we observed that SP870 was more reliable and legible than PGS1.21 for monitoring resistance as only one resistance allele had to be taken into account for the SNP-based marker as opposed to four for the SSR. In addition, a total as high as 24 alleles for 110 allele-combinations were observed for PGS1.21, making reading more difficult and less transferable. This confirms the relevancy of this new marker-set for screening apricot seedlings.

Table 1. Occurrence of the SNP and SSR alleles in the 765 accessions. Each of the two alleles of a given genotype is counted individually

\begin{tabular}{|c|c|c|c|c|c|c|c|}
\hline Marker & & SP870r & SP870s & SP353r & SP353s & SP871r & SP871s \\
\hline & Allele & G & C & T & A & T & C \\
\hline PGS1.21 & 340 & 101 & 0 & - & - & - & - \\
& 338 & 47 & 0 & - & - & - & - \\
\hline & 336 & 2 & 0 & - & - & - & - \\
\hline & 330 & 4 & 2 & - & - & - & - \\
\hline & others & 2 & 1372 & - & - & - & - \\
\hline ZP002 & 108 & - & - & 181 & 1 & & - \\
\hline & 113 & - & - & 1 & 1347 & - & - \\
\hline PGS1.24 & 101 & - & - & - & - & 166 & 0 \\
\hline & others & - & - & - & - & 1 & 1363 \\
\hline
\end{tabular}

In this study we have developed an SNP-based set of three markers likely to replace the SSR-based set currently used for discriminating between apricot seedlings susceptible to PPV and possible resistant ones. We have compared both sets and the information given by the SNP appears more reliable and legible than the SSRs. In addition it was more convenient, easier and faster to implement and quite cheaper as well. As a result, it is now routinely used for early selection of apricot seedlings in our breeding programs aimed at selecting PPV resistant cultivars.

\section{References}

Soriano et al. (2012) Mol Breed 30:1017-1026 Zuriaga et al. (2013) Mol. Plant Pathol. 14:663-677 Decroocq et al. (2014). Tree Genet. Genomes, $10(5)$ Mariette et al. (2016). The New Phytologist. 209: 773-784. 